exists in certain stocks from which it may be possible to select or breed varieties combining the resistance with acceptable commercial characters.

During the latter part of the work we have been in touch with the staff of the National Vegetable Research Station, and we are indebted to them for much interest in the parsnip trials. As part of their work will deal with parsnip canker, it was decided to offer them any material in which they were interested and this offer was accepted. Accordingly, at the lifting in March 1953 roots from each of our seven stocks of parsnips were sent to Wellesbourne for seeding there and in the hope that they will be of some value in any further research on canker. This communication is written to explain the origin and history of the stocks from the spring of 1949 onwards.

Donald E. Green

Royal Horticultural Socièty's Gardens,

M. ANN HewletT

Wisley, Ripley,

Woking. Jan. 28.

'Jones, A. P., Nature, 171, 574 (1953).

'Green, D. F., and Hewlett, M. A., Agriculture, 57, 216 (1950).

3 Stirrup, H. II., and Roebuck, A., J. Min. Agric., 33, 824 (1926-27).

\section{Factors influencing the Emergence of Heterodera rostochiensis Larva}

MANY investigators have reported a considerable variation in the seasonal rate of hatching of eggs from the cysts of Heterodera rostochiensis, in the presence of root diffusate.

Both Fenwick ${ }^{1}$ and Lownsbery ${ }^{2}$ have shown that the direct effect of temperature on cysts in vitro, in the presence of root diffusate, caused an increase in the amount of hatching with rise in temperature. They found the optimum rate of hatch was between $21^{\circ}$ and $25^{\circ} \mathrm{C}$., and both reported inhibition of hatching or dormancy at temperatures of $30^{\circ}-33^{\circ} \mathrm{C}$.

Recent investigations in this laboratory indicate, however, that seasonal variations in hatching are not simply the result of a direct correlation between temperature and hatching. It has been shown that the rate and amount of hatching from viable cysts of the same age maintained at $15^{\circ} \mathrm{C}$. is profoundly influenced by the maximum temperatures to which the moist cysts have been subjected previously, before the addition of root diffusate. Except for a very brief note in a paper by Calam, Raistrick and Todd $^{3}$, there appears to be no record of this indirect effect of temperature on moist cysts.

Samples of cysts of the same age were kept in water at temperatures of $15^{\circ}, 23^{\circ}$ and $29^{\circ} \mathrm{C}$. for 34 days, and afterwards at $15^{\circ} \mathrm{C}$. Two days later root diffusate was added to all samples. Four days afterwards, the cysts which had been pre-heated at $23^{\circ} \mathrm{C}$. produced a hatch twenty to thirty times as great as the hatch from the cysts kept at $15^{\circ} \mathrm{C}$, while none hatched from the cysts pre-heated at $29^{\circ} \mathrm{C}$. All attempts to hatch eelworms from samples of cysts which had been kept at $29^{\circ} \mathrm{C}$., by the addition of root diffusate, failed until twenty days after removing to the lower temperature of $15^{\circ} \mathrm{C}$. The hatch was then very rapid and somewhat similar to that from cysts pre-heated at $23^{\circ} \mathrm{C}$. Small amounts of hatching also occurred after the twentieth day in control batches of cysts pre-heated at $29^{\circ} \mathrm{C}$. and to which no root diffusate had been added, in numbers similar to the emergence from eysts kept at $15^{\circ} \mathrm{C}$.
These hatching results may explain the unexpected tomato and potato crop failures which occasionally occur at moderate viable cyst population levels, and would seem to explain the absence of winter dormancy reported by Fenwick ${ }^{4}$ and the winter dormancy noted by Lownsbery ${ }^{2}$ in the United States, where accord. ing to him the mean soil temperature of 6 in. depth averaged $22^{\circ} \mathrm{C}$. during the summer.

This work is being continued and these results wil be reported more fully elsewhere.

East of Scotland College of Agriculture,

E. DUNN 13 George Square,

Edinburgh 8. Feb. 14.

${ }^{1}$ Fenwick, D. W., J. Helminth, 25 (1/2), 37 (1951).

${ }^{2}$ Lownsbery, B. F., Phytopath., 41 (10), 889 (1951).

${ }^{3}$ Calam, C. T., Raistrick, H., and Todd, A. R., Biochem. J., 45, 513 (1949).

4 Fenwick, D. W., Nature, 171, 47 (1953).

\section{Effect of Oxygen on the Fixation of Nitrogen by Azotobacter}

RECENT studies on the fixation of molecular nitrogen by both anaerobic ${ }^{1}$ and aerobic ${ }^{2}$ heterotrophic nitrogen-fixing bacteria indicate that ammonia is the first stable compound formed. This raises the question whether the necessary hydrogen is derived from water or from the metabolite. The latter source seems the more likely, especially since the union of metabolic hydrogen and molecular nitrogen to form ammonia could yield a considerable amount of free energy. If this were so, members of the anaerobic genus Clostridium would be expected to fix nitrogen more efficiently than the aerobe Azotobacter, which passes its metabolic hydrogen to oxygen. Results obtained in this laboratory show that Clostridium is, in fact, capable of more efficient nitrogen fixation than Azotobacter ${ }^{3}$. Again, if metabolic hydrogen is involved in the reduction of molecular nitrogen then, with a nitrogen-fixing aerobe, oxygen must compete with nitrogen for this hydrogen and so depress fixation. Conflicting results have been reported for the effect of partial pressure of oxygen on nitrogen fixation by $A$ zotobacter ${ }^{4}$.

The effect of oxygen upon nitrogen fixation was examined in this laboratory using one strain of Azotobacter vinelandii and one of Azotobacter chroococcum. Both were slow-growing strains, and were grown in shallow liquid layers to allow ready diffusion of gases into and out of solution. The medium was a 1 per cent sucrose salts solution at $p \mathrm{H} 7$, and contained yeast extract. $10-\mathrm{ml}$. aliquots were poured into 10-cm. Petri dishes, inoculated and incubated at $28^{\circ} \mathrm{C}$. in sealed jars with different partial pressures of oxygen. The atmospheres in the jars were renewed frequently until the cultures were harvested after 21 days. Inoculated controls were acidified, stored and analysed with the cultures by micro-Kjeldahl method. At 4 per cent oxygen, A. vinelandii fixed $23.5 \mathrm{mgm}$. nitrogen, and $A$. chroococcum $21.6 \mathrm{mgm}$. nitrogen, per gm. sucrose supplied; at 20 per cent oxygen the fixation was $8 \cdot 1 \mathrm{mgm}$. and $7 \cdot 4 \mathrm{mgm}$. nitrogen respectively. These results showed greatly increased nitrogen-fixing efficiency with decreased partial pressures of oxygen (significant at the 0.1 per cent level).

When considered with the reported inhibition of nitrogen fixation by molecular hydrogen ${ }^{5}$, the inhibition by oxygen suggests that it is dehydrogenase hydrogen which is passed to nitrogen. Thus nitrogen 